\title{
Minimally invasive endoscopic repair of refractory lateral skull base cerebrospinal fluid rhinorrhea: case report and review of the literature
}

\author{
Brandon Lucke-Wold, PhD, ${ }^{1}$ Erik C. Brown, MD, PhD, ${ }^{2}$ Justin S. Cetas, MD, PhD, ${ }^{2}$ \\ Aclan Dogan, MD, ${ }^{2}$ Sachin Gupta, MD, ${ }^{3}$ Timothy E. Hullar, MD, ${ }^{3}$ Timothy L. Smith, MD, MPH, ${ }^{3}$ and \\ Jeremy N. Ciporen, MD²
}

${ }^{1}$ School of Medicine, West Virginia University, Morgantown, West Virginia; and Departments of ${ }^{2}$ Neurological Surgery and ${ }^{3}$ Otolaryngology-Head and Neck Surgery, Oregon Health \& Science University, Portland, Oregon

\begin{abstract}
Cerebrospinal fluid (CSF) leaks occur in approximately $10 \%$ of patients undergoing a translabyrinthine, retrosigmoid, or middle fossa approach for vestibular schwannoma resection. Cerebrospinal fluid rhinorrhea also results from trauma, neoplasms, and congenital defects. A high degree of difficulty in repair sometimes requires repetitive microsurgical revisions-a rate of $10 \%$ of cases is often cited. This can not only lead to morbidity but is also costly and burdensome to the health care system. In this case-based theoretical analysis, the authors summarize the literature regarding endoscopic endonasal techniques to obliterate the eustachian tube (ET) as well as compare endoscopic endonasal versus open approaches for repair. Given the results of their analysis, they recommend endoscopic endonasal ET obliteration (EEETO) as a first- or second-line technique for the repair of CSF rhinorrhea from a lateral skull base source refractory to spontaneous healing and CSF diversion. They present a case in which EEETO resolved refractory CSF rhinorrhea over a 10-month follow-up after CSF diversions, wound reexploration, revised packing of the ET via a lateral microscopic translabyrinthine approach, and the use of a vascularized flap had failed. They further summarize the literature regarding studies that describe various iterations of EEETO. By its minimally invasive nature, EEETO imposes less morbidity as well as less risk to the patient. It can be readily implemented into algorithms once CSF diversion (for example, lumbar drain) has failed, prior to considering open surgery for repair. Additional studies are warranted to further demonstrate the outcome and cost-saving benefits of EEETO as the data until now have been largely empirical yet very hopeful. The summaries and technical notes described in this paper may serve as a resource for those skull base teams faced with similar challenging and otherwise refractory CSF leaks from a lateral skull base source.
\end{abstract}

https://thejns.org/doi/abs/10.3171/2017.12.FOCUS17664

KEY WORDS eustachian tube; CSF leak repair; endoscopic; transnasal; skull base

$\mathrm{C}$ EREBROSPINAL fluid (CSF) leaks occur in approximately $10 \%$ of patients undergoing a translabyrinthine approach, retrosigmoid craniectomy, or middle fossa approach for vestibular schwannoma resection, ${ }^{19}$ with no significant difference in the incidence of leaks among these approaches. ${ }^{1}$ Indeed, CSF leakage is the most common complication of vestibular schwannoma resection, ${ }^{2}$ but it can also be observed in trauma, neoplasms, and congenital malformations. ${ }^{3,21}$ The eustachian tube (ET) is the final common pathway associated with these lateral skull base surgical approaches and the most common route for CSF leakage presenting as CSF rhinorrhea. Patients will often present with persistent rhinorrhea, which can contribute to headache as well as infections such as meningitis. ${ }^{18}$ A slight majority of such leaks can be managed conservatively with lumbar drain placement and bed rest, but many other cases are not so easily solved. ${ }^{5}$ Indeed, surgical techniques such as packing the middle ear and ET from a posterior approach preemptively at the time of initial surgery are now standard practice to minimize the risk of such a complication, although their efficacy has been questioned. ${ }^{6}$ Refractory cases often lead to a return

ABBREVIATIONS CSF = cerebrospinal fluid; EEETO = endoscopic endonasal eustachian tube obliteration; ET = eustachian tube.

SUBMITTED November 2, 2017. ACCEPTED December 14, 2017.

INCLUDE WHEN CITING DOI: 10.3171/2017.12.FOCUS17664. 
to the operating room for surgical intervention and repair. Traditionally, this involved an open exploration of the surgical site with direct repair of any identifiable CSF leak. Multiple techniques have been proposed and tested for CSF rhinorrhea correction, in particular, a less invasive approach to avoid the well-known risks associated with reoperation. Most notable among such techniques is endoscopic endonasal eustachian tube obliteration (EEETO), whose multiple forms are discussed in the literature.9,20 Taghi and colleagues pioneered the endoscopic double seal technique, which has been successful for refractory CSF leaks. ${ }^{20}$ Lemonnier et al. reported the first case series on EEETO outcomes, and only 1 of 7 patients required a repeat procedure. ${ }^{9}$

Endoscopic endonasal ET obliteration is a promising technique with theoretical benefits such as its minimally invasive nature, potentially increased cost-effectiveness with a shorter hospital stay, and greater patient satisfaction. Multiple iterations of this technique have been proposed and tested over the years; however, the procedure that is most suitable and provides the most reliable outcomes has not been identified. Here, in this technical synthesis, we identify those techniques that have been used as variations of EEETO and report on a case in which we successfully employed our own variation of the EEETO when a CSF leak persisted despite multiple other invasive interventions.

\section{Methods}

In this literature review, our goal was to identify all articles that described some form of what we referred to as a variation of EEETO, that is, a technique in which inter- vention on the ET was performed from an endonasal approach. Studies aimed at reducing or obliterating the ET lumen, such as in repairing CSF leaks or treating a patulous ET, were included. As our aim was to assess the utility of such techniques, the review was limited to studies in which the procedure was performed on patients or cadavers. Two of the authors (E.C.B. and B.L.W.) each searched PubMed for articles as well as the reference lists of each identified article; there was no restriction concerning the time period, and example search terms included "eustachian tube," "endonasal," and "CSF leak repair." The two authors independently approved the articles identified to enhance validity, with any disagreements settled by another author (J.N.C.). Information regarding the technique performed, the number of patients involved, and the results of the technique along with any overall benefits described therein was extracted and tabulated.

\section{Results}

A literature search yielded a total of 8 studies on endoscopic endonasal approaches to the ET (Table 1). Three studies were performed to treat patients with patulous ET. ${ }^{4,13,17}$ Four studies were performed for the treatment of patients with CSF rhinorrhea. ${ }^{8,9,16,20}$ One study was a cadaveric feasibility study aimed at developing a technique for the repair of CSF rhinorrhea. ${ }^{10}$ Across the 7 studies with live patients, the success rate was high; the minimum success rate for treatment of a patulous ET was $85 \%$ and that for CSF rhinorrhea was $88 \%$. The exact technique performed varied across the studies but consisted of some combination of closure of the nasopharyngeal ET orifice with cauterization, plugging, suture cerclage, and/or a tis-

TABLE 1. Review of the literature describing endoscopic endonasal approaches to obstruct the eustachian tube

\begin{tabular}{|c|c|c|c|}
\hline $\begin{array}{l}\text { Authors } \\
\& \text { Year }\end{array}$ & Technique & $\begin{array}{l}\text { No. of } \\
\text { Patients }\end{array}$ & Results/Benefits \\
\hline $\begin{array}{l}\text { O'Connor \& } \\
\quad \text { Shea, } 1981\end{array}$ & $\begin{array}{l}\text { Symptomatic patulous ET; endoscopic endonasal application of silver nitrate } 15 \mathrm{~mm} \\
\text { into ET for } 20 \text { mins }\end{array}$ & 7 & Success/simple, safe, reversible \\
\hline $\begin{array}{l}\text { Kwartler et al., } \\
1996\end{array}$ & $\begin{array}{l}\text { Persistent CSF rhinorrhea following translabyrinthine craniectomy; endoscopic } \\
\text { endonasal ET orifice incision, inversion, \& cauterization }\end{array}$ & 1 & Success/simple, safe, effective \\
\hline $\begin{array}{l}\text { Doherty \& Slat- } \\
\text { tery, } 2003\end{array}$ & $\begin{array}{l}\text { Symptomatic patulous ET; endoscopic endonasal fat packing w/ cautery of pharyn- } \\
\text { geal orifice }\end{array}$ & 2 & Success/simple, safe, effective \\
\hline $\begin{array}{l}\text { Orlandi \& Shel- } \\
\quad \text { ton, } 2004\end{array}$ & $\begin{array}{l}\text { CSF rhinorrhea in } 2 \text { patients: in one following transcochlear \& suboccipital craniecto- } \\
\text { my \& in the other following retrosigmoid craniectomy; endoscopic endonasal cau- } \\
\text { tery of ET at depth of } 2-3 \mathrm{~mm} \text { followed by suture cerclage of pharyngeal orifice }\end{array}$ & 2 & $\begin{array}{l}\text { Success/simple, safe, effective, } \\
\text { claimed potential for reversibility }\end{array}$ \\
\hline $\begin{array}{l}\text { Rotenberg et } \\
\text { al., } 2013\end{array}$ & $\begin{array}{l}\text { Patulous ET; multilayered endoscopic endonasal technique involving combination of } \\
\text { fat plugging, endoluminal cauterization up to } 10-\mathrm{mm} \text { depth, \& suture cerclage }\end{array}$ & $11^{*}$ & $\begin{array}{l}12 \text { of } 14 \text { ears w/ success/simple, } \\
\text { safe, effective }\end{array}$ \\
\hline $\begin{array}{l}\text { Manes et al., } \\
2013\end{array}$ & $\begin{array}{l}\text { Feasibility study showing that semi-rigid catheter can be placed via an endoscopic } \\
\text { endonasal approach to occlude ET lumen }\end{array}$ & $5 \dagger$ & $\begin{array}{l}\text { Technically feasible/easy to perform } \\
\text { w/ right tools }\end{array}$ \\
\hline $\begin{array}{l}\text { Taghi et al., } \\
2015\end{array}$ & $\begin{array}{l}\text { CSF rhinorrhea following retrosigmoid suboccipital craniotomy; endoscopic double } \\
\text { seal obliteration of ET orifice, rotational flap w/ cartilage plug }\end{array}$ & 1 & Success/simple, safe, effective \\
\hline $\begin{array}{l}\text { Lemonnier et } \\
\quad \text { al., } 2015\end{array}$ & $\begin{array}{l}\text { Patients w/ recalcitrant CSF rhinorrhea following lat skull base surgery; endoscopic } \\
\text { endonasal pharyngeal ET orifice cauterization w/ suture cerclage }\end{array}$ & 9 & $\begin{array}{l}7 \text { of } 9 \text { had successful ops w/ no } \\
\text { CSF leak; of remaining 2, } 1 \text { had } \\
\text { successful repeat procedure/min- } \\
\text { imally invasive, safe, \& effective }\end{array}$ \\
\hline
\end{tabular}

\footnotetext{
* Fourteen ears.

$\dagger$ Five cadaveric heads (bilaterally).
} 
sue flap; the cadaveric study was unique in that it explored the feasibility of catheterizing the ET from an endonasal approach. The literature review, with reported outcomes listed in Table 1, serves as a basis for future investigations into standardizing an EEETO technique.

\section{Illustrative Case}

History and Examination

A 69-year-old woman with a body mass index of 26.3 $\mathrm{kg} / \mathrm{m}^{2}$ and a medical history significant only for hypertension presented with asymmetrical hearing loss and intermittent vertigo that had developed over the course of several months. At that time, she sought medical care, and an audiogram revealed nonserviceable hearing loss in the right ear. Brain MRI revealed a homogeneously enhancing lesion involving the internal auditory canal and cerebellopontine angle. A consult with radiation oncology to discuss stereotactic radiosurgery and appointments with neurotology were scheduled. The patient decided to pursue serial imaging with observation. When her hearing continued to worsen, she was referred to neurosurgery and resection was discussed. She preferred resection over stereotactic radiosurgery. Magnetic resonance imaging characteristics were consistent with a vestibular schwannoma (Fig. 1), and resection was scheduled.

A standard translabyrinthine approach was performed with complete resection of the tumor. Of note, the closure technique involved temporal muscle free graft occlusion of the ET, free abdominal fat graft placement, fibrin glue, and a pedicled suboccipital muscle and fascia closure, followed by prophylactic lumbar drainage for 3 days postoperatively, all to prevent CSF leakage. The procedure was 469 minutes in duration, from incision to completion of closure.

Postoperative imaging revealed gross-total resection of the lesion (Fig. 2). The patient was discharged home after 3 days of prophylactic lumbar drainage and successfully passing a 24-hour clamp trial of the drain without CSF rhinorrhea or leakage from the surgical site. Within
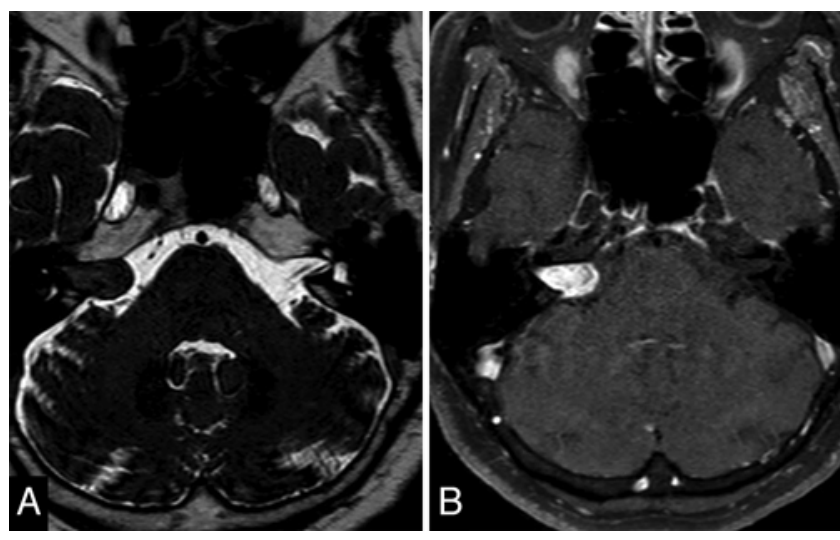

FIG. 1. Preoperative axial T2-weighted (A) and contrast-enhanced T1weighted (B) images were obtained at the level of the internal auditory canal. A largely homogeneously enhancing lesion at the right cerebellopontine angle and extending into the right internal auditory canal has the typical appearance of a vestibular schwannoma, which was the preliminary diagnosis preoperatively.
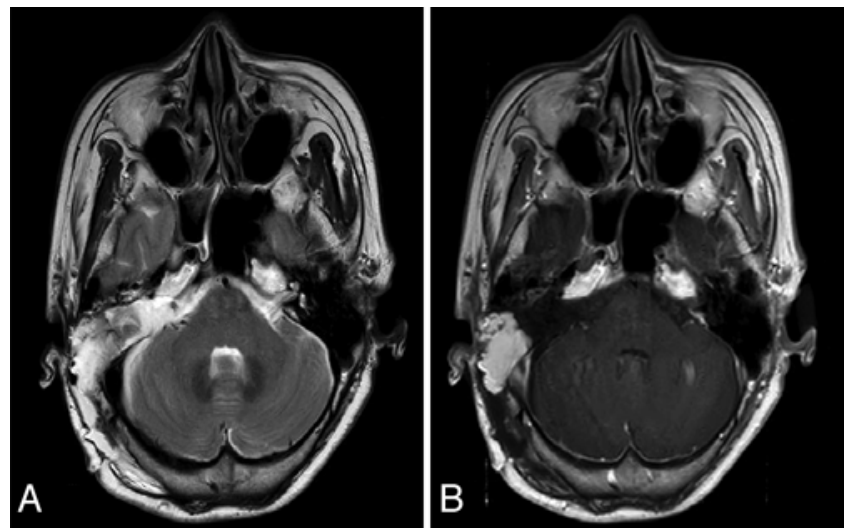

FIG. 2. Postoperative axial T2-weighted (A) and contrast-enhanced T1weighted (B) images were obtained at the level of the internal auditory canal. Note that a large portion of the petrous temporal bone, including the middle ear and other structures of the cochleovestibular systems, has been removed and filled with packing material, including fat and muscle. There is no evidence of residual contrast-enhancing lesion, indicating gross-total resection.

2 weeks postoperatively, the patient presented with newonset CSF rhinorrhea ipsilateral to the translabyrinthine approach. It appeared to be treated successfully with CSF diversion via repeat placement of a lumbar drain and bed rest. After another 6 weeks, however, the patient required readmission for recurrent CSF rhinorrhea. Imaging at that time was concerning for an increased ventricle size, which was consistent with postoperative hydrocephalus. This responded to placement of a lumbar drain over 2 days, and we determined that long-term CSF diversion was required and would probably be beneficial. A ventriculoperitoneal shunt with a programmable Medtronic Strata valve at a setting of 1.5 was placed for treatment of the hydrocephalus, and this was expected to address her CSF rhinorrhea as well; a programmable valve was chosen to avoid future shunt-related procedures should the patient require adjustments to the valve. She was readmitted just a few weeks after shunt placement with recurrent rhinorrhea yet again and CT evidence of pneumocephalus (Fig. 3). This provided further evidence that her rhinorrhea indeed had an intracranial origin and was most likely CSF. At this time, a repeat right-sided mastoidectomy, repacking of the ET tympanic orifice, and placement of both a pedicled temporoparietal fascial flap and abdominal fat graft harvest were performed.

\section{Technique}

At 31 days after the revision, the patient again experienced recurrent CSF rhinorrhea. A head CT scan showed a small amount of fluid in the right sphenoid sinus as well as a small fracture line of uncertain etiology within the posterior table wall over that sinus. A CT myelogram was concerning for a retrocochlear cell communication with the ET lumen. A nuclear medicine radiographic shunt patency study, also known as a "shuntogram," demonstrated a patent and functioning ventriculoperitoneal shunt. The shunt valve was dialed down to a setting of 0.5 to increase shunt flow; however, this did not resolve the patient's CSF rhinorrhea. The potential risks and benefits of 


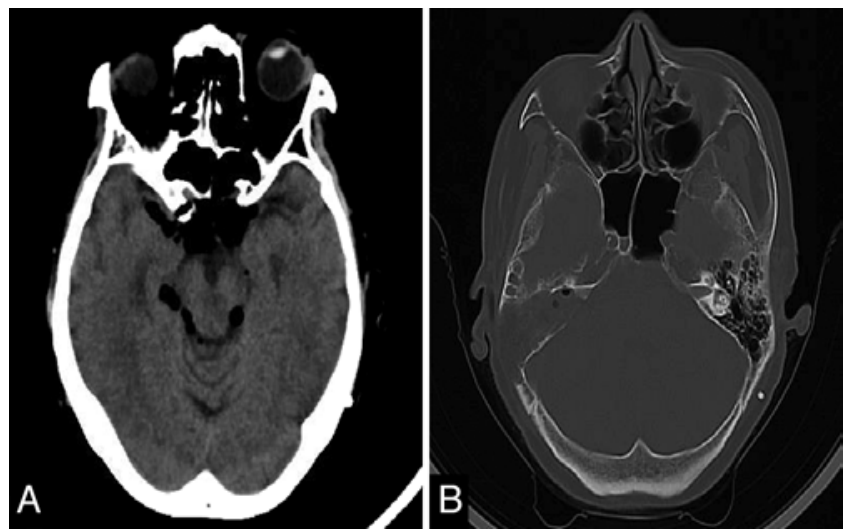

FIG. 3. Imaging was performed a few weeks after shunt placement when the patient had recurrent rhinorrhea, with CT windowed for soft tissue (A) and for bone (B). In the soft-tissue window, air in the intracranial space, also known as "pneumocephalus," is clearly visualized. The bone window, at a level more inferior to that of the soft-tissue window, shows a small amount of air within the surgical bed as well as a small amount of fluid within the right maxillary sinus, indicating that fluid had tracked into the nasal sinuses from a site near to or within the surgical bed.

an open middle fossa approach versus a variation of the EEETO were discussed among the patient, her family, and colleagues, and a decision to proceed with EEETO was reached.

A right vascularized nasoseptal flap was prepared, and repair of the suspected right sphenoid CSF leak was undertaken endoscopically with successful flap placement. The focus of further repair was then placed on obliterating the ET lumen. The nasopharyngeal ET orifice was accessed via a unilateral endoscopic approach through the right nares. The ET was dilated and cauterized using a Bovie suction cautery. The ET was packed with AlloDerm (LifeCell Corp.), and a cerclage stitch was placed at the nasopharyngeal orifice of the ET.

At 6 weeks postoperatively, however, the patient presented again with recurrent CSF rhinorrhea. The team and patient agreed to revision of the EEETO. During this reoperation, intrathecal fluorescein was used and demonstrated a leak through the ET. The AlloDerm graft was removed from the nasopharyngeal orifice via an endonasal approach. The posterior aspect of the inferior turbinate was trimmed with a sinus shaver. The ET was internally coagulated with a suction Bovie at the nasopharyngeal orifice via an endonasal approach. Fascia lata harvested from the thigh was used to pack the ET, followed by Surgicel (Ethicon) and Avitene (CR Bard), again at the nasopharyngeal orifice. Two ET cerclage sutures securing a piece of muscle fascia were placed with the aid of laparoscopic knot pushers. Surgical glue was placed over the cerclage stitches. A supplemental video (Video 1) is provided to show this repeat EEETO procedure.

VIDEO 1. Video showing revision of the EEETO. Fluorescein is seen exiting the nasopharyngeal orifice of the ET near the beginning of the video. Subsequently, the ET lumen near the nasopharyngeal orifice was cauterized, packed, and closed with suture cerclage. This finally led to an excellent result for the patient after a long process involving multiple procedures for a persistent CSF leak. Copyright Jeremy N. Ciporen. Published with permission. Click here to view.
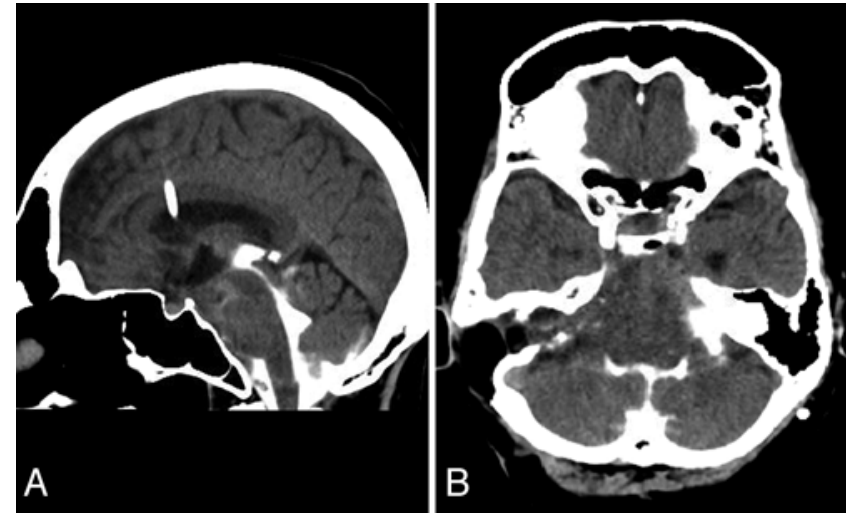

FIG. 4. Computed tomography scanning with soft-tissue windows in the sagittal (A) and axial (B) planes was performed 37 days following the repeat EEETO. There is no evidence of pneumocephalus or fluid in the sinuses. Note the well-placed ventriculoperitoneal shunt catheter.

\section{Outcome}

The patient recovered well after this second, more extensive EEETO and was discharged a few days following the operation. Serial follow-up appointments were scheduled with otolaryngology and neurosurgery with intermittent imaging (MRI and CT) to evaluate the tumor resection as well as to monitor for any evidence of pneumocephalus (Figs. 4 and 5). At 10 months postoperatively, the patient was symptom free with no recurrent CSF leak.

\section{Discussion}

Most EEETO approaches have been used for recalcitrant CSF leaks. ${ }^{20}$ Because a slight majority of CSF leaks can be successfully managed conservatively, delayed EEETO implementation is rational. ${ }^{9}$ The benefits of EEETO include a quick rate of surgical recovery, no need to reenter the original surgical site, and a reported success rate greater than $88 \%$ in treating a CSF leak. Furthermore, such approaches do not require cranioplasty or the placement of titanium mesh, which limits potential routes of infection. ${ }^{11}$ If obliteration of the ET is performed
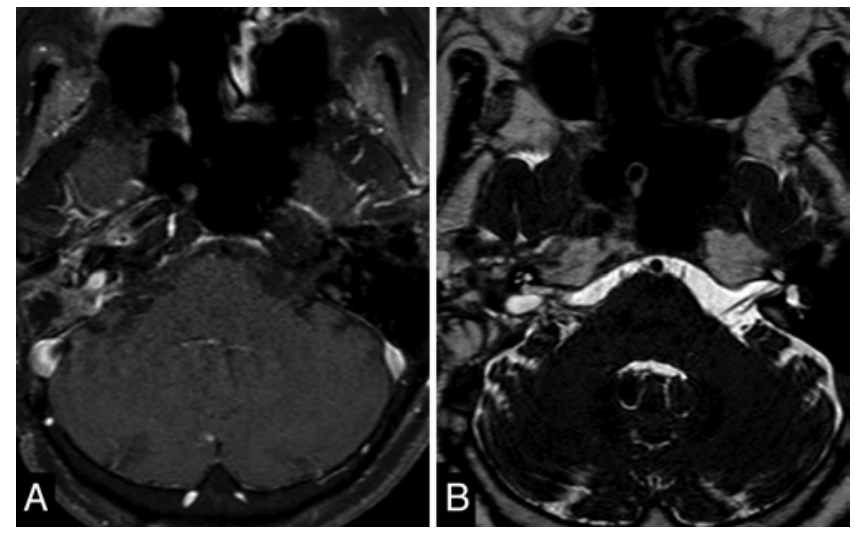

FIG. 5. Six months post-EEETO, contrast-enhanced T1-weighted (A) and T2-weighted (B) MRI was performed. There was no evidence of a recurrent contrast-enhancing lesion. Neither was there pooling of fluid in the sinuses, nor any evidence of pneumocephalus. 
at the time of initial surgery, there is concern for potential tympanic membrane retraction with decreased compliance. ${ }^{18}$ Also, the patient can develop recurrent serous otitis media, which often requires placement of tympanostomy tubes. ${ }^{15}$ These potential complications have not been observed with EEETO approaches, although more extended monitoring of outcomes is needed. Some investigators are optimistic, for example, Orlandi and Shelton, who claim that their iteration of EEETO is potentially reversible and that the conductive hearing loss associated with the serous otitis media that can result from obstruction of the nasopharyngeal orifice is resolved with a hearing aid. ${ }^{16}$ The precise risks of EEETO in patients with serviceable hearing require further investigation. The patient described herein had nonserviceable hearing loss at presentation and had no rhinorrhea 10 months after EEETO. Preliminary evidence also suggests that EEETO approaches are more cost-effective than traditional approaches. Traditional approaches involve reentering the surgical site, unroofing the internal auditory canal, and packing the site and surrounding mastoid air cells with bone wax, fat grafts, or muscle patches. These traditional techniques have a failure rate of $38 \%,{ }^{12}$ whereas previously discussed EEETO approaches have a failure rate $<20 \%$. The improved treatment success, as well as the speed and minimally invasive nature of the procedure, adds to the cost savings of EEETO. Further research is needed to determine which of the described EEETO techniques is most successful in preventing recurrent CSF leak and should be standardized going forward.

The patient presented herein had persistent CSF leak following gross-total resection of a vestibular schwannoma-despite the ET packing, abdominal fat graft, and CSF diversion during the initial surgery to prophylactically prevent CSF rhinorrhea. Subsequent CSF diversion was performed first with a lumbar drain and later with a programmable ventriculoperitoneal shunt as well as wound reexploration and repacking of the ET and middle ear. An abdominal fat harvest and a pedicled temporal fascial graft were used for the patient's revision, yet she was still one of the $38 \%$ of patients who have treatment failure. Given the serious concern for potential meningitis with long-term CSF leakage, further repair techniques were considered. In this case, CSF was draining into the ET more anteromedial than we could access through the translabyrinthine approach. Because of the potential risks and benefits of the situation, the most reasonable next step, based on a review of the relevant literature, was to proceed with EEETO versus a middle fossa craniotomy. By using EEETO with fascia lata and muscle cerclage, we were able to achieve complete obliteration of the ET without having to reenter the original operative site or create a new operative site. This decreased the risk for infection and was successful in managing the leak, whereas other more traditional approaches had failed.

The excellent result achieved with EEETO in this case, however, required two EEETO attempts that followed a long and frustrating course of refractory CSF rhinorrhea with multiple procedures that included two attempts at packing the ET posteriorly. Our second attempt at the EEETO included more aggressive internal cautery of the ET, more extensive packing, and the use of two rather than one cerclage stitch. Of course, we suspect that had we performed the EEETO in this manner on the first attempt, the excellent result may have been achieved sooner. If a method were developed to catheterize the entire luminal length of the ET, any point along the ET could potentially be accessed for obliteration. One key unanswered question going forward is how to develop a standardized endoscopic technique for ET obliteration that can be readily implemented at multiple centers. Intrinsic to this question is the appreciation of natural variation in ET anatomy. Olander and colleagues mapped the length between the ET lumen and the internal carotid artery at various points for endoscopic techniques to address ET dilatory dysfunction..$^{14}$ From their work using MRI, they determined the average distance from the internal carotid artery to the cartilaginous and bony ET junctional point was $4.3 \mathrm{~mm}$ (range 1.6-10.4 $\mathrm{mm}$ ), to the mid cartilaginous ET was $25 \mathrm{~mm}$ (range 9.0-61.6 $\mathrm{mm}$ ), and to the nasopharyngeal orifice was $62 \mathrm{~mm}$ (range 34.3-84.4 mm). This anatomical mapping was necessary to avoid injury to the internal carotid artery during the operations, especially near the junctional point. Similarly, it will be important to map surgical ET anatomical landmarks in relation to its major curvature to predict safe catheter advancement. Cadaveric studies should be undertaken to determine anatomical variance and provide guidance for operative planning. Three important parameters will need to be determined: isthmus diameter, ET length, and curvature of the ET. The work of Manes et al. has begun to answer some of these questions. ${ }^{10}$ By determining these anatomical matters, the surgeon will be able to safely deliver the device into the lumen for obliteration without damaging vulnerable nearby structures. Such studies will also pave the way for preoperative planning using advanced imaging. ${ }^{22}$

\section{Conclusions}

In summary, EEETO as outlined in this case report and literature review reveals a viable, cost-effective, and highly effective option for managing recalcitrant CSF leakage from a lateral skull base source. The EEETO was successful in our case after more traditional approaches had failed. We believe that new techniques can be developed to allow standardization of the procedure and expand utility. Going forward, cadaveric studies will be necessary to help guide definitive surgical planning for this new approach. Furthermore, long-term outcomes must be tracked with greater patient numbers to determine the true efficacy of the technique as compared with more traditional treatments. Finally, cost-analysis studies should be undertaken to determine how much money per hospital visit an institution could save by implementing EEETO. We believe that the data obtained until now indicate that EEETO is promising as a second-line approach for the repair of CSF rhinorrhea from a lateral skull base defect, prior to open surgical intervention.

\section{Acknowledgments}

We thank Shirley McCartney, $\mathrm{PhD}$, for editorial assistance. We also acknowledge the anonymous reviewers of our manuscript, who provided insightful comments to further improve its quality and utility. 


\section{References}

1. Becker SS, Jackler RK, Pitts LH: Cerebrospinal fluid leak after acoustic neuroma surgery: a comparison of the translabyrinthine, middle fossa, and retrosigmoid approaches. Otol Neurotol 24:107-112, 2003

2. Crowson MG, Cunningham CD III, Moses H, Zomorodi AR, Kaylie DM: Preoperative lumbar drain use during acoustic neuroma surgery and effect on CSF leak incidence. Ann Otol Rhinol Laryngol 125:63-68, 2016

3. Daele JJ, Goffart Y, Machiels S: Traumatic, iatrogenic, and spontaneous cerebrospinal fluid (CSF) leak: endoscopic repair. B-ENT 7 (Suppl 17):47-60, 2011

4. Doherty JK, Slattery WH III: Autologous fat grafting for the refractory patulous eustachian tube. Otolaryngol Head Neck Surg 128:88-91, 2003

5. Fishman AJ, Marrinan MS, Golfinos JG, Cohen NL, Roland JT Jr: Prevention and management of cerebrospinal fluid leak following vestibular schwannoma surgery. Laryngoscope 114:501-505, 2004

6. Jacob A, Bortman JS, Robinson LL Jr, Yu L, Dodson EE, Welling DB: Does packing the eustachian tube impact cerebrospinal fluid rhinorrhea rates in translabyrinthine vestibular schwannoma resections? Otol Neurotol 28:934-938, 2007

7. Kram YA, Lustig LR, McDermott MW, Cheung SW: Transcanal blind sac closure of the external auditory canal after skull base surgery to treat CSF leak: technique and results. Otol Neurotol 36:307-310, 2015

8. Kwartler JA, Schulder M, Baredes S, Chandrasekhar SS: Endoscopic closure of the eustachian tube for repair of cerebrospinal fluid leak. Am J Otol 17:470-472, 1996

9. Lemonnier LA, Tessema B, Kuperan AB, Jourdy DN, Telischi FF, Morcos JJ, et al: Managing cerebrospinal fluid rhinorrhea after lateral skull base surgery via endoscopic endonasal eustachian tube closure. Am J Rhinol Allergy 29:207-210, 2015

10. Manes RP, Kutz JW, Isaacson B, Batra PS: Technical feasibility of endoscopic eustachian tube catheter placement: a cadaveric analysis. Am J Rhinol Allergy 27:314-316, 2013

11. Manjila S, Weidenbecher M, Semaan MT, Megerian CA, Bambakidis NC: Prevention of postoperative cerebrospinal fluid leaks with multilayered reconstruction using titanium mesh-hydroxyapatite cement cranioplasty after translabyrinthine resection of acoustic neuroma. J Neurosurg 119:113120,2013

12. Nutik SL, Korol HW: Cerebrospinal fluid leak after acoustic neuroma surgery. Surg Neurol 43:553-557, 1995

13. O'Connor AF, Shea JJ: Autophony and the patulous eustachian tube. Laryngoscope 91:1427-1435, 1981

14. Olander H, Järnstedt J, Poe D, Kivekäs I: Critical distance between the cartilaginous Eustachian tube and the internal carotid artery. Eur Arch Otorhinolaryngol 274:73-77, 2017

15. Oliaei S, Mahboubi H, Djalilian HR: Transmastoid approach to temporal bone cerebrospinal fluid leaks. Am J Otolaryngol 33:556-561, 2012

16. Orlandi RR, Shelton C: Endoscopic closure of the eustachian tube. Am J Rhinol 18:363-365, 2004

17. Rotenberg BW, Busato GM, Agrawal SK: Endoscopic ligation of the patulous eustachian tube as treatment for autophony. Laryngoscope 123:239-243, 2013

18. Saliba I, Shinghal T, Nehme J, Dufour JJ: Eustachian tube obliteration in translabyrinthine vestibular schwannoma excision: cerebrospinal fluid rhinorrhea and middle ear status. J Otolaryngol Head Neck Surg 40:367-375, 2011

19. Selesnick SH, Liu JC, Jen A, Newman J: The incidence of cerebrospinal fluid leak after vestibular schwannoma surgery. Otol Neurotol 25:387-393, 2004

20. Taghi AS, Bentley M, Kuchai R, Saleh HA: Double seal technique to obliterate the eustachian tube orifice: a novel method for the treatment of recalcitrant cerebrospinal fluid leak. J Laryngol Otol 129:1028-1031, 2015

21. Teo DT, Tan TY, Eng SP, Chan YM: Spontaneous cerebrospinal fluid otorrhoea via oval window: an obscure cause of recurrent meningitis. J Laryngol Otol 118:717-720, 2004

22. Terzi S, Beyazal Çeliker F, Özgür A, Çeliker M, Beyazal M, Demirci M, et al: The evaluation of eustachian tube paratubal structures using magnetic resonance imaging in patients with chronic suppurative otitis media. Acta Otolaryngol 136:673-676, 2016

\section{Disclosures}

The authors report no conflict of interest concerning the materials or methods used in this study or the findings specified in this paper.

\section{Author Contributions}

Conception and design: all authors. Acquisition of data: Ciporen, Lucke-Wold, Brown. Analysis and interpretation of data: Ciporen, Lucke-Wold, Brown. Drafting the article: Ciporen, Lucke-Wold, Brown. Critically revising the article: all authors. Reviewed submitted version of manuscript: Ciporen, Lucke-Wold, Brown, Cetas, Gupta, Hullar, Smith. Approved the final version of the manuscript on behalf of all authors: Ciporen. Statistical analysis: Ciporen. Administrative/technical/material support: Ciporen. Study supervision: Ciporen.

\section{Supplemental Information \\ Videos \\ Video 1. https://vimeo.com/250126839.}

\section{Correspondence}

Jeremy N. Ciporen: Oregon Health \& Science University, Portland, OR.ciporen@ohsu.edu. 